\title{
Frontal Glucose Hypometabolism in Abstinent Methamphetamine Users
}

\author{
Seog Ju Kim', In Kyoon Lyoo*,', Jaeuk Hwang', Young Hoon Sung', Ho Young Lee², Dong Soo Lee², \\ Do-Un Jeong' and Perry F Renshaw ${ }^{3}$ \\ 'Department of Psychiatry, Seoul National University College of Medicine and Hospital, Seoul, Korea; ${ }^{2}$ Department of Nuclear Medicine, Seoul \\ National University College of Medicine and Hospital, Seoul, Korea; ${ }^{3}$ McLean Hospital Brain Imaging Center, Belmont, MA, USA
}

\begin{abstract}
Changes in relative regional cerebral glucose metabolism (rCMRglc) and their potential gender differences in abstinent methamphetamine (MA) users were explored. Relative rCMRglc, as measured by ${ }^{18}$ F-fluorodeoxyglucose positron emission tomography, and frontal executive functions, as assessed by Wisconsin card sorting test (WCST), were compared between 35 abstinent MA users and 21 healthy comparison subjects. In addition, male and female MA users and their gender-matched comparison subjects were compared to investigate potential gender differences. MA users had lower rCMRglc levels in the right superior frontal white matter and more perseveration and nonperseveration errors in the WCST, relative to healthy comparison subjects. Relative rCMRglc in the frontal white matter correlated with number of errors in the WCST in MA users. In the subanalysis for gender differences, lower rCMRglc in the frontal white matter and more errors in the WCST were found only in male MA users, not in female MA users, relative to their gender-matched comparison subjects. The current findings suggest that MA use causes persistent hypometabolism in the frontal white matter and impairment in frontal executive function. Our findings also suggest that the neurotoxic effect of MA on frontal lobes of the brain might be more prominent in men than in women.

Neuropsychopharmacology (2005) 30, 1383-139I, advance online publication, 23 February 2005; doi: I 0.1038/sj.npp. I 300699
\end{abstract}

Keywords: methamphetamine; frontal lobe; positron emission tomography; brain mapping; neuropsychological tests; sex characteristics

\section{INTRODUCTION}

Methamphetamine (MA) is a highly addictive substance (Woolverton et al, 1984) and MA abuse has been increasing worldwide (Shaw, 1999). It has been reported to have a long-term neurotoxic effect on dopaminergic neurons (Preston et al, 1985; Wilson et al, 1996). Frontal and subcortical areas have been suggested as more vulnerable areas to the neurotoxic effects of MA, as these regions are closely associated with the dopaminergic system (Sekine et al, 2003; Volkow et al, 2001b).

Prior ${ }^{18} \mathrm{~F}$-fluorodeoxyglucose positron emission tomography (FDG-PET) studies have reported changes of relative regional cerebral glucose metabolism (rCMRglc) in MA

This study was submitted at the 2004 College on Problems of Drug Dependence annual meeting that was held in San Juan, Puerto Rico on June 12-17, 2004

*Correspondence: Professor IK Lyoo, Department of Psychiatry, Seoul National University Hospital, 28 Yongon-dong, Chongno-gu, Seoul, I | 0-744, South Korea, Tel: + 8222072 3173, Fax: + 82236720677 , E-mail: inkylyoo@yahoo.com

Received 5 October 2004; revised 16 December 2004; accepted 21 December 2004

Online publication: 14 January 2005 at http://www.acnp.org/citations/ NPPO I | 405040470/default.pdf users. Volkow et al (2001c) have reported higher cortical and lower subcortical rCMRglc in abstinent MA users. London et al (2004) have reported abnormal rCMRglc in limbic and paralimbic areas in recently detoxified MA users.

Other prior brain imaging studies have reported that MA users have various kinds of abnormalities in frontal areas (Chang et al, 2002; Ernst et al, 2000a; Nordahl et al, 2002; Paulus et al, 2003, 2002; Sekine et al, 2003; Thompson et al, 2004; Volkow et al, 2001a). In addition, our recently completed studies have shown that MA users have significantly lower prefrontal gray matter density (Chung et al, 2004) and decreased regional cerebral blood flow $(\mathrm{rCBF})$ in anterior cingulate cortex compared to healthy comparison subjects (Hwang et al, 2004).

Impairment of neuropsychological function has also been reported in MA users (Kalechstein et al, 2003; Vorhees et al, 1994). Paulus et al $(2002,2003)$ have reported decisionmaking dysfunctions in MA users. They have also reported a failure of activation in prefrontal cortices during decisionmaking tests in MA users, as measured by functional magnetic resonance imaging (fMRI). However, the detailed association of frontal executive functions and rCMRglc in frontal lobes of MA users has not been reported.

Potential gender difference has been suggested in neurotoxic effects of MA (Hall and Broderick, 1991). Males 
have been reported to be more susceptible to neurotoxic effects of MA in animal studies (Hirata et al, 1996; Wagner et al, 1993). Recently, Chang et al (2002) have reported that male MA users had decreased $\mathrm{rCBF}$ and female MA users had increased $\mathrm{rCBF}$ in occipital and midline structures, relative to gender-matched comparison subjects (Chang et $a l, 2002)$. They have also reported that the decrease of frontal $\mathrm{rCBF}$ was more prominent in male MA users. However, to the best of our knowledge, there have been no prior studies investigating gender differences on the cerebral glucose metabolism of MA users.

Based on prior imaging and neuropsychological studies, we hypothesized that abstinent MA users would have decreased frontal rCMRglc, as measured by FDG-PET, and impaired frontal executive function, as assessed by the Wisconsin card sorting test (WCST), relative to healthy comparison subjects. We also hypothesized that, in accord with previous studies reporting potential gender difference in MA neurotoxicity, decreased frontal rCMRglc and poor frontal executive function would be more pronounced in male MA users than in female MA users.

\section{PATIENTS AND METHODS}

\section{Subjects}

Inclusion criteria were (1) age 19-49 years, (2) DSM-IV MA abuse or dependence as determined by Structured Clinical Interview for DSM-IV (SCID-IV), as administered by experienced psychiatrists, (3) abstinence for at least 4 weeks, and (4) cumulative intravenous MA use over $50.0 \mathrm{~g}$. Exclusion criteria were (1) current or past serious medical or neurological illness, (2) current or past history of Axis I psychiatric disorder: schizophrenia, bipolar disorder, and other psychotic disorders, and any current Axis I disorder requiring psychotropic medications, as identified by SCIDIV, (3) antisocial or borderline personality disorders, as identified by the Personality Disorder Questionnaire-4, (4) lifetime exposure to any other DSM-IV dependence- or abuse-related drugs, except nicotine, caffeine, alcohol drinking, and prescribed medications, and (5) contraindications to magnetic resonance (MR) scanning. Study subjects were instructed to abstain from alcohol, any prescribed medications, or herbal medications for at least 2 weeks before the PET scan. Smoking was prohibited for $2 \mathrm{~h}$ before the PET scan, as a prolonged cessation of smoking may induce nicotine withdrawal, which can confound PET findings in smokers.

In all, 35 MA users (28 males and seven females) and 21 healthy comparison subjects (15 males and six females) were recruited through advertisements at local newspapers and at the Korean Association against Drug Abuse. To investigate potential gender effects on the MA use, we compared rCMRglc and frontal executive functions between male MA users $(n=28)$ and male comparison subjects $(n=15)$, and between female MA users $(n=7)$ and female comparison subjects $(n=6)$. Study procedures including PET and the WCST were conducted in Seoul National University Hospital, Seoul, South Korea. Study protocol was approved by the Institutional Review Boards at Seoul National University Hospital and McLean Hospital, Massachusetts, USA. After providing a complete description of the study to the subjects, written informed consent was obtained.

Information regarding clinical and demographic variables was derived from the MA users and healthy comparison subjects by research psychologists and research psychiatrists. The Addiction Severity Index (ASI) (McLellan et al, 1980) was administered to 30 MA users.

\section{Wisconsin Card Sorting Test}

A research neuropsychologist conducted WCST to examine impairment in frontal executive function for 33 MA users and 21 healthy comparison subjects. Two MA users (37- and 42-year-old males) who had participated in the PET study did not elect to participate in the neuropsychological test. The WCST assesses the executive function, the ability to form abstract concepts, to shift and maintain set, and to utilize feedback (Heaton et al, 1993; Yoo et al, 2000). Numbers of perseveration errors, nonperseveration errors, and total errors (perseveration errors + nonperseveration errors) were used for statistical analysis.

\section{Acquisition of Positron Emission Tomography}

Subjects were scanned using an ECAT EXACT 47 scanner (Siemens-CTI, Knoxville, TN, USA), which had an intrinsic resolution of $5.2 \mathrm{~mm}$ full width at half maximum (FWHM) and simultaneously imaged 47 contiguous transverse planes with a thickness of $3.4 \mathrm{~mm}$ for a longitudinal field view of $16.2 \mathrm{~cm}$. Before injection of the tracer, a 15-min transmission scan was performed using triple GE-68 rod sources to correct attenuation. Emission scanning started after intravenous injection of $370 \mathrm{MBq}(10 \mathrm{mCi})$ of ${ }^{18} \mathrm{~F}-\mathrm{FDG}$ and continued for $30 \mathrm{~min}$ without earplugs or eye pads. All ${ }^{18} \mathrm{~F}$ FDG PET scans were performed in a dimly lit room with minimal auditory stimulation during both injection and PET scanning, with the subject in a supine position with eyes closed so as to minimize confounding effects of any activities. At the beginning of PET scanning, subjects were instructed not to think about or do anything in particular during the scanning. Gathered data were reconstructed in a $128 \times 128 \times 47$ matrix with a pixel size of $2.1 \times 2.1 \times 3.4 \mathrm{~mm}$ by means of a filtered back-projection algorithm employing a Shepp-Logan filter with a cutoff frequency of 0.3 cycles/ pixel.

\section{Imaging Data Analysis}

Spatial preprocessing and statistical analysis were performed using Statistical Parametric Mapping (SPM 99) (Institute of Neurology, University College of London, UK) implemented in Matlab (Mathworks Inc., USA) (Friston et al, 1995a). All reconstructed images were spatially normalized into the MNI (Montreal Neurological Institute, McGill University, CA) standard template to remove the intersubject anatomical variability (Friston et al, 1995b; Tarairach and Tournoux, 1988). Affine transformation was performed to determine the 12 optimal parameters to register the brain on the template. Subtle differences between the transformed image and the template were removed by the nonlinear registration method using the 
weighted sum of the predefined smooth basis functions used in discrete cosine transformation.

Spatially normalized images were smoothed by convolution with an isotropic Gaussian kernel with $16 \mathrm{~mm}$ FWHM to increase the signal-to-noise ratio and to accommodate the variations in subtle anatomical structures. Normalization was performed to remove between-subject variability of global metabolism (proportional scaling in SPM). After spatial and count normalization, significant differences of rCMRglc between MA users and healthy comparison subjects were estimated at every voxel using $t$-statistics. Parameters to define regions of significant differences were conservatively set. These include $p$-value $=0.05$ (corrected for multiple comparisons), height threshold $t=4.88$, and the extent threshold $=50$ voxels. For volume of interest (VOI) count analysis on the significantly different voxel cluster, normalized counts were calculated using VOI module of SPM. However, for the thoroughness of report, differences at the uncorrected $p$ level of 0.001 were also presented.

\section{Statistical Analysis}

Group differences in variables involving continuous data were computed using independent $t$-tests. Between-group comparisons involving categorical data were assessed using Fisher's exact test for $2 \times k$ table. Associations between continuous variables were calculated using Pearson correlation analysis. Statistical significance was defined at 0.05 and two-tailed. Stata 7.0 for Windows was used for computations.

First, MA users and healthy comparison subjects were compared. In the subanalysis, comparisons between male MA users and male comparison subjects and between female MA users and female comparison subjects were conducted to explore potential gender effects.

\section{RESULTS}

\section{Demographic and Clinical Data}

There were no significant differences in age, sex composition, prevalence of social alcohol drinking, or handedness between 35 abstinent MA users (28 men and seven women, $35.5 \pm 6.4$ years) and 21 healthy comparison subjects (15 men and six women, $33.2 \pm 6.4$ years). Prevalence of current cigarette smoking was greater in MA users, relative to healthy comparison subjects (Fisher's exact test, $p=0.02$ ). There was a significant difference in educational level between MA users and healthy comparison subjects (independent $t$-test, $\mathrm{df}=54, t=10.1, p<0.01$ ). It was practically impossible to recruit healthy comparison subjects with educational levels comparable to those in MA users. Instead, we matched the socioeconomic status of parents between groups as in prior drug studies (Pope $e t$ al, 2001). There were no significant differences in the pack years of cigarette smoking between the smokers in the MA user group $(n=21)$ and the smokers in the healthy comparison group $(n=6)$. All MA users were intravenous users. Detailed drug-related variables of abstinent MA users are described in Table 1.
Table I Demographic Characteristics of MA Users and Healthy Comparison Subjects

\begin{tabular}{|c|c|c|c|c|}
\hline \multirow[b]{2}{*}{ Demographic variables } & \multicolumn{2}{|c|}{ MA users $(n=35)$} & \multicolumn{2}{|c|}{$\begin{array}{l}\text { Healthy comparisor } \\
\text { subjects }(n=2 I)\end{array}$} \\
\hline & Mean (n) & SD (\%) & Mean (n) & SD (\%) \\
\hline Age (years) & 35.5 & 6.4 & 33.2 & 6.4 \\
\hline Sex (male) & 28 & $80.0 \%$ & 15 & $71.4 \%$ \\
\hline Handedness (right) & 29 & $82.9 \%$ & 18 & $85.7 \%$ \\
\hline Educational level (years)* & 10.0 & 2.1 & 15.3 & 1.4 \\
\hline \multicolumn{5}{|l|}{ Parent's SES } \\
\hline High & 6 & $17.1 \%$ & 6 & $28.6 \%$ \\
\hline Middle & 13 & $37.1 \%$ & 7 & $33.3 \%$ \\
\hline Low & 16 & $45.7 \%$ & 8 & $38.1 \%$ \\
\hline Social alcohol drinking & 25 & $71.4 \%$ & 14 & $66.7 \%$ \\
\hline Current smoking* & 21 & $60.0 \%$ & 6 & $28.6 \%$ \\
\hline Total cumulative dose (mg) & 355.24 & 446.32 & - & - \\
\hline Average daily dose (mg) & 0.62 & 0.45 & - & - \\
\hline Age of initial MA use (years) & 22.57 & 5.74 & - & - \\
\hline Duration of MA use (months) & 69.78 & 44.97 & - & - \\
\hline Abstinence period (months) & 19.14 & 27.20 & - & - \\
\hline \multicolumn{5}{|l|}{ Addiction severity ${ }^{\mathrm{a}}$} \\
\hline Medical & 0.21 & 0.29 & - & - \\
\hline Employment & 0.60 & 0.33 & - & - \\
\hline Alcohol & 0.13 & 0.21 & - & - \\
\hline Drug & 0.07 & 0.05 & - & - \\
\hline Legal & 0.17 & 0.19 & - & - \\
\hline Family & 0.16 & 0.14 & - & - \\
\hline
\end{tabular}

There were no significant differences in total cumulative dose, average daily dose, mean abstinence period, ASI scores, handedness, or prevalence of social alcohol drinking and current cigarette smoking between male and female MA users. Male MA users were significantly older than female MA users (independent $t$-test; $\mathrm{df}=33, t=3.82, p<0.01$ ).

There were no significant differences in age, handedness, or prevalence of social alcohol drinking and current cigarette smoking between 28 male MA users $(37.2 \pm 5.1$ years) and 15 male comparison subjects ( $36.1 \pm 4.8$ years).

There were no significant differences in age, handedness, or prevalence of social alcohol drinking between seven female MA users (28.5 \pm 6.8 years) and six female comparison subjects (26.1 \pm 3.8 years). Prevalence of cigarette smoking was larger in female MA users, relative to female comparison subjects (Fisher's exact test, $p=0.03$ ).

\section{Comparison between Methamphetamine Users and Healthy Comparison Subjects}

There were significant decreases in rCMRglc in the right superior frontal white matter (Talairach coordinates $(x, y$, 


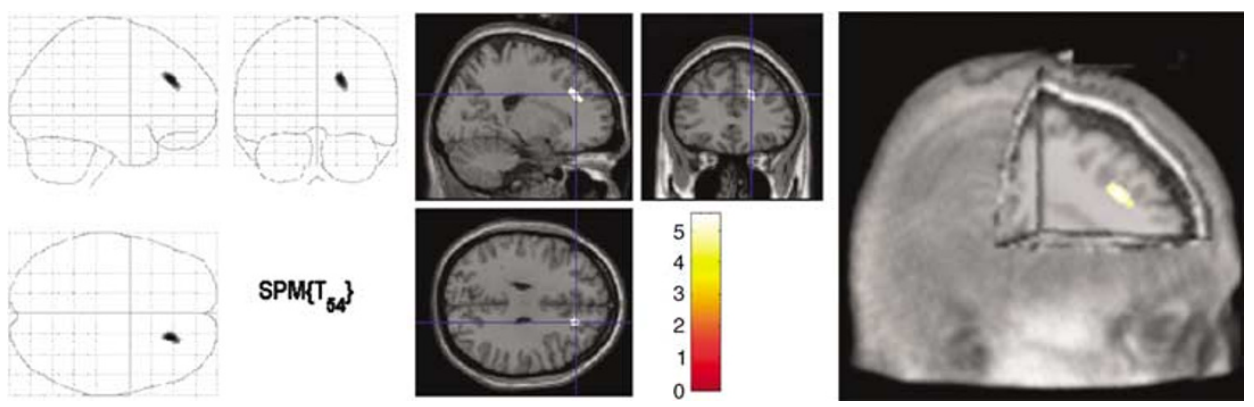

Figure I Region of decreased rCMRglc in MA users relative to healthy comparison subjects. Relative rCMRglc decrease in MA users ( $n=35$ ) relative to healthy comparison subjects $(n=2 I)$ is depicted in glass brain projection (left panel), slice view (middle panel), and the brain of one healthy volunteer (right panel). Reduction of rCMRglc in right superior frontal white matter (Talairach coordinates $(x, y, z): 20,34,30)$ in MA users relative to healthy comparison subjects is shown. SPM map ( $t>4.88$, extent threshold $=50$ voxels, $p<0.05$ corrected for multiple comparisons) is provided. MA: methamphetamine; rCMRglc: regional cerebral glucose metabolism; SPM: statistical parametric mapping.

$z): 20,34,30 ; 6.1 \%$ decrease) in MA users relative to the healthy comparison subjects (corrected $p<0.05, t>4.88$ ) (Figure 1). The nearest gray matter region was the right middle frontal cortex (Brodmann area, BA, 9). When uncorrected $p<0.001$ was used for defining significant differences, there were significant decreases in rCMRglc in the left medial frontal gray matter (BA 8) and bilateral subgyral white matters in MA users relative to healthy comparison subjects.

MA users had significantly more total errors, perseveration errors, and nonperseveration errors in the WCST relative to the healthy comparison subjects (independent $t$-test; $t=3.29, \mathrm{df}=52, p<0.01 ; t=2.91, \mathrm{df}=52, p<0.01$; $t=2.81, \mathrm{df}=52, p<0.01$, respectively).

The number of total errors, perseveration errors, and nonperseveration errors in the WCST negatively correlated with the rCMRglc value in the area of significant difference (ie right middle frontal white matter) in MA users (Pearson's correlation, $r=-0.45, n=33, p<0.01$; $r=-0.54, n=33, p<0.01 ; \quad r=-0.36, \quad n=33, p=0.04$, respectively) (Figure 2). Age had no significant correlations with the rCMRglc value in the area of significant difference or total errors, perseveration errors, or nonperseveration errors in WCST in MA users.

There were no significant differences in rCMRglc in the area of significant difference or the number of errors in the WCST between MA users who were smokers $(n=21)$ and those who were not $(n=14)$. In addition, there were no significant differences in rCMRglc in the area of significant difference or the number of errors in the WCST between smokers $(n=6)$ and nonsmokers $(n=15)$ in the healthy comparison group.

We conducted multiple regression analyses (dependent variables: WCST and PET raw scores; independent variables: diagnosis, education). Similar results were produced when educational levels were covaried. In addition, there were no within-group correlations between education levels and number of errors in the WCST or rGMRglc value in the area of significant difference in MA users and in healthy volunteers.

\section{Findings in Male Methamphetamine Users}

There were significant decreases in the rCMRglc value in the area of significant difference in male MA users relative to male comparison subjects (independent $t$-test, $t=6.43$, $\mathrm{df}=41, p<0.01$ ) (Figure 3). Male MA users had significantly more total errors, perseveration errors, and nonperseveration errors in WCST relative to male comparison subjects (independent $t$-test, $t=2.90, \mathrm{df}=39, p<0.01$; $t=2.59, \mathrm{df}=39, p=0.01 ; t=2.76, \mathrm{df}=39, p<0.01$, respectively) (Figure 3).

The number of total errors and perseveration errors in WCST negatively correlated with rCMRglc values in the area of significant difference in male MA users (Pearson's correlation, $r=-0.47, n=26, p=0.02 ; r=-0.54, n=33$, $p<0.01$, respectively). The number of nonperseveration errors in the WCST was not significantly correlated with rCMRglc values in the area of significant difference in male MA users (Pearson's correlation, $r=-0.31, n=26$, $p=0.12$ ).

\section{Findings in Female Methamphetamine Users}

There were no significant differences in rCMRglc values in the area of significant difference between female MA users and female comparison subjects (independent $t$-test, $t=0.63, \mathrm{df}=11, p=0.54)$. In addition, there were no significant differences in total errors, perseveration errors, and nonperseveration errors in the WCST between female MA users and female comparison subjects (independent $t$-test, $t=1.34, \mathrm{df}=11, p=0.21 ; t=1.24, \mathrm{df}=11, p=0.24$; $t=0.54, \mathrm{df}=11, p=0.60$, respectively).

There were no significant correlations of the number of errors (total, perseveration, and nonperseveration errors) in the WCST with rCMRglc values in the area of significant difference in female MA users (Pearson's correlation, $r=-0.13, \quad n=7, \quad p=0.78 ; \quad r=-0.10, \quad n=7, \quad p=0.83$; $r=-0.19, n=7, p=0.68$, respectively).

\section{DISCUSSION}

We report decreased rCMRglc in the frontal white matter and impairment in frontal executive function in MA users. The levels of these impairments correlated with each other. In subanalysis to investigate potential gender differences, our findings of decreased frontal rCMRglc and impaired frontal executive function were found only in male MA users, but not in female MA users. 

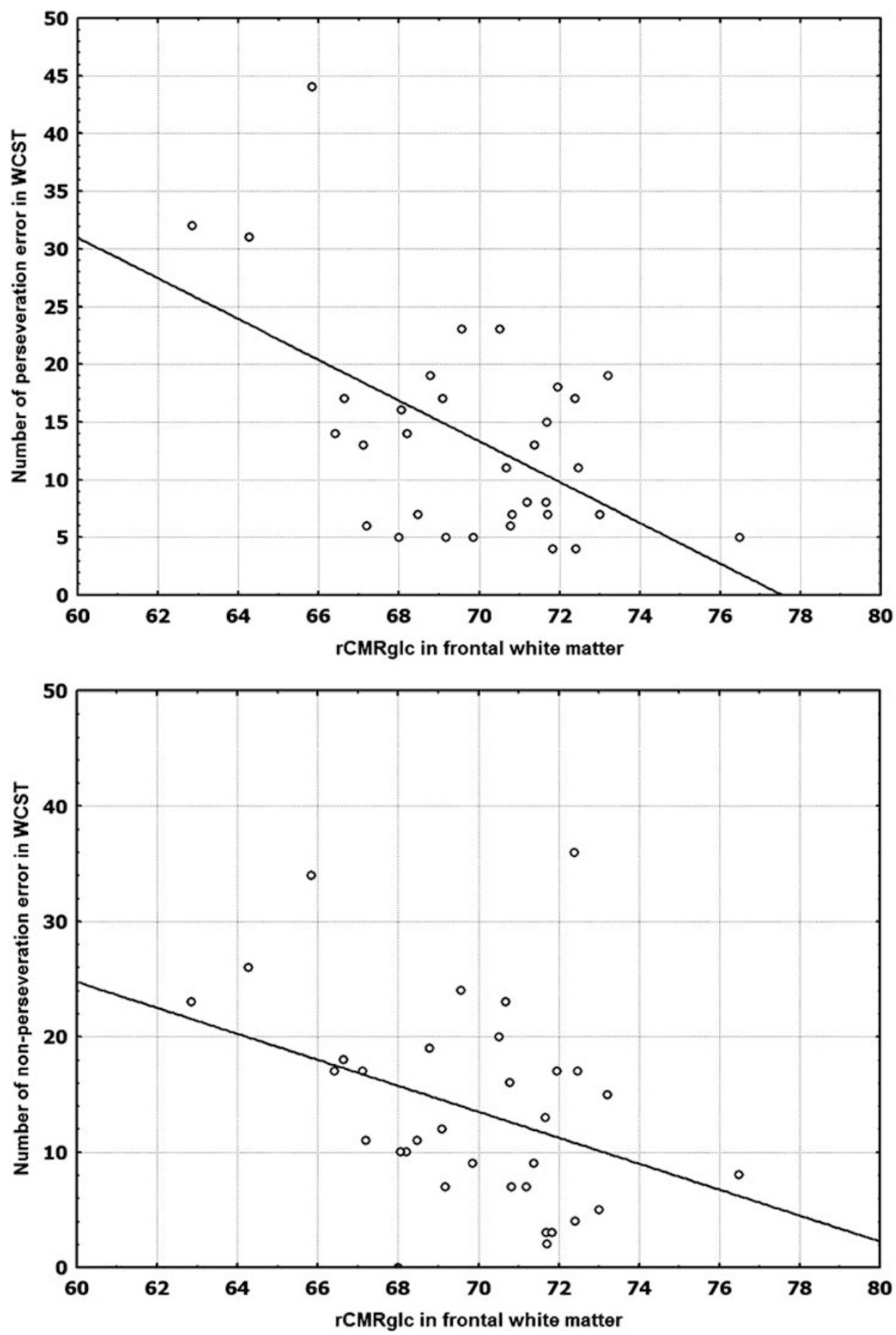

Figure 2 Correlations of number of perseveration and nonperseveration errors in WCST with rCMRglc in right frontal white matter (region with significant rCMRglc difference between MA users $(n=35)$ and healthy comparison subjects $(n=21)$ (Talairach coordinates $(x, y, z)$ : $20,34,30)$ ) of MA users $(n=33)$. Negative correlation between rCMRglc in right frontal white matter and number of perseveration errors in MA users ( $n=33)$ (upper panel) (Pearson's correlation, $r=-0.54, n=33, p<0.0 \mathrm{I}$ ), and also between rCMRglc in right frontal white matter and number of nonperseveration errors in MA users $(n=33)$ (lower panel) (Pearson's correlation, $r=-0.36, n=33, p=0.04)$ is presented. MA: methamphetamine; rCMRglc: regional cerebral glucose metabolism; WCST: Wisconsin Card Sorting Test.

To the best of our knowledge, the current report is the first study in MA users investigating the gender-MA interactions on the rCMRglc. Strengths of our study include (1) all MA subjects were without comorbid axis I or II disorders for which structural brain deficits have been reported and (2) all MA subjects were not only without current or lifetime diagnosis of other substance abuse/ dependence but also without any lifetime exposure to any other DSM-IV dependence- or abuse-related drugs, except nicotine, caffeine, alcohol, and prescribed medications.

In accord with our first hypothesis, the MA user had decreased rCMRglc in frontal white matter. Prior imaging studies other than FDG-PET in MA users have reported various kinds of frontal abnormalities; decreased dopamine 

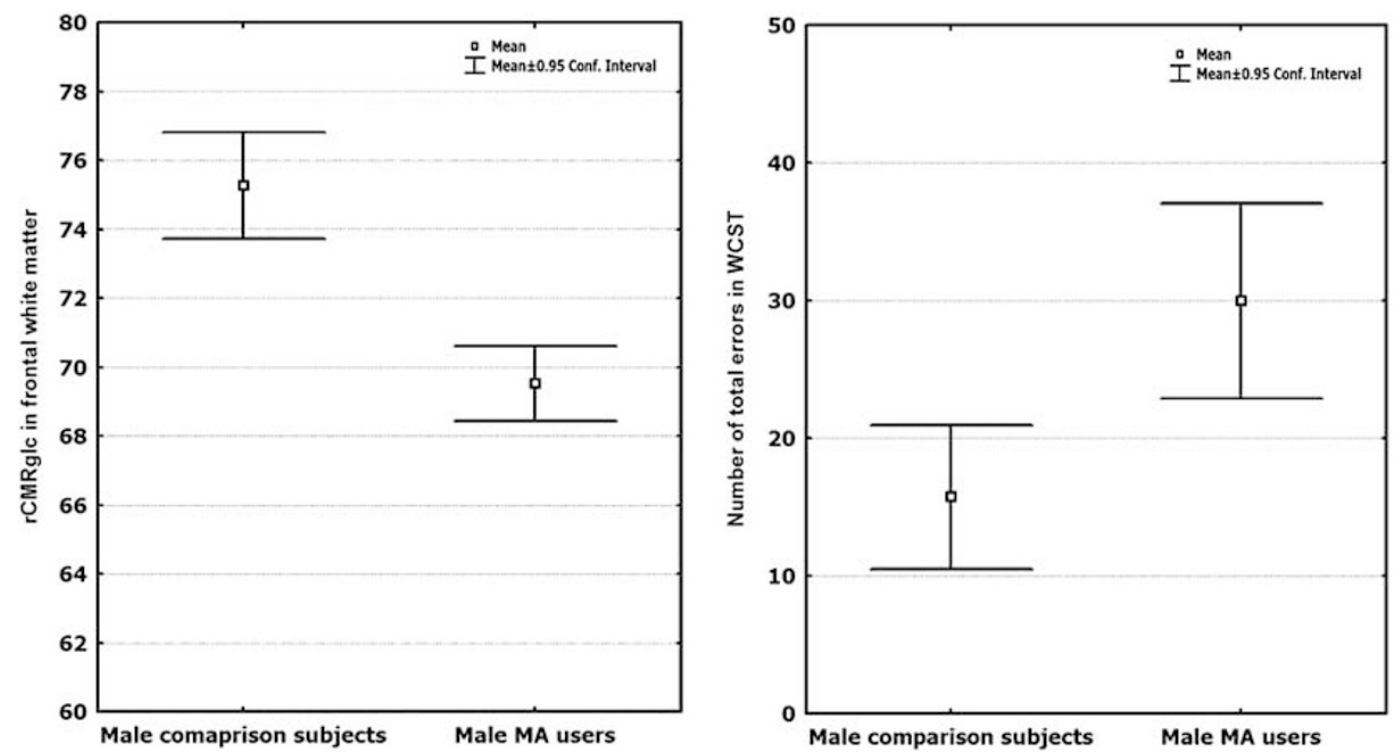

Figure 3 Relative rCMRglc in right frontal white matter (region with significant rCMRglc difference between MA users $(n=35)$ and healthy comparison subjects $(n=21)$ (Talairach coordinates $(x, y, z): 20,34,30)$ ) and the number of total errors in WCST in male comparison subjects and male MA users, Significant differences in rCMRglc in right frontal white matter between male MA users $(n=28)$ and male comparison subjects ( $n=15)$ (left panel) (independent $t$-test, $t=6.43, \mathrm{df}=4 \mathrm{I}, p<0.0 \mathrm{I}$ ), and also in number of total error in WCST between male MA users $(n=26)$ and male comparison subjects $(n=15)$ (right panel) (independent $t$-test, $t=2.90, \mathrm{df}=39, p<0.0 \mathrm{I}$ ) are presented. MA: methamphetamine; $r C M R g l c$ : regional cerebral glucose metabolism WCST: Wisconsin Card Sorting Test.

transporter level (Sekine et al, 2003), lesser task-related activation (Paulus et al, 2002, 2003), decreased rCBF (Chang et al, 2002; Hwang et al, 2004), decreased relative $N$-acetyl aspartate (NAA) level (Ernst et al, 2000a; Nordahl et al, 2002), and gray matter deficits (Thompson et al, 2004; Chung et al, 2004). Our finding of hypometabolism in the frontal white matter provides additional evidence for frontal abnormality in MA users.

Prior FDG-PET studies have also reported that MA users had altered rCMRglc (London et al, 2004; Volkow et al, 2001c). Volkow et al (2001c) have reported that MA abusers had relative glucose hypometabolism in the striatum and thalamus and hypermetabolism in the parietal cortex. London et al (2004) have reported abnormal glucose metabolism in the limbic and paralimbic areas in MA users. In the current study, we report decreased rCMRglc in the frontal white matter.

Locations of the reported hypometabolism do not coincide exactly from one study to another. Differences in the abstinence period of MA subjects in each study might be the most important reason for different locations of altered metabolism among studies, as rCMRglc in MA users has been reported to be affected by the length of abstinence periods (Wang et al, 2004). While most MA subjects were abstinent for 2 weeks to 5 months in Volkow's study and for 4-7 days in London's study, MA subjects in the present study were abstinent for much longer periods (mean abstinence period $=19.1$ months). Discrepancies of the locations may be also attributable to the different clinical characteristics of MA users, as MA users in the current study were all intravenous MA users and without lifetime exposure to other major street drugs. Furthermore, brain areas with significant hypometabolism in the different studies may have some close functional connections, as shown in a study reporting correlations between decreased dopamine D2 receptor levels in striatum and orbitofrontal rCMRglc in MA users (Volkow et al, 2001a).

Our findings of rCMRglc decrease in the frontal white matter, but not in the gray matter, may seem unusual, as rCMRglc of white matter is generally lower compared to that of gray matter. However, we found decreased rCMRglc in other frontal regions including gray matter of MA users when a less conservative criterion, that is, uncorrected $p$ level of 0.001 , was applied. In accordance with our findings, a decreased level of NAA, a marker of neuronal viability, in frontal white matter has also been reported in MA users (Ernst et al, 2000a). Therefore, our findings suggest that impairments in the frontal lobe of MA users are more profound in the white matter than in the gray matter.

In addition to hypometabolism of the frontal white matter, we also report the impairment of frontal executive function in MA users. The closest gray matter areas to the areas with significantly decreased rCMRglc in our study corresponded with the dorsolateral prefrontal cortex, which is associated with frontal executive function. Inefficient decision-making strategy in MA users, which is indicated by more errors in the WCST in the present study, is consistent with prior studies reporting impairment of the frontal executive function in MA users (Kalechstein et al, 2003; Paulus et al, 2002, 2003).

Poor performances of MA users in the WCST in the current study correlate with decreased rCMRglc in frontal white matter. These correlations between frontal executive function and frontal metabolism in our study are in accord with prior fMRI studies reporting the failure of normal prefrontal activation during decision-making tasks in MA users (Paulus et al, 2002, 2003). Therefore, the current finding of decreased rCMRglc in frontal white matter may underlie the impairment in frontal executive function. 
In line with our second hypothesis, the decreased rCMRglc in the frontal white matter and the impairment in the frontal executive function were found only in male MA users. Our finding of gender difference in rCMRglc in frontal white matter in MA users is consistent with a recent study reporting more pronounced hypoperfusion of frontal regions in male MA users (Chang et al, 2002). Gender differences in cerebral perfusion and metabolites of frontal white matter have also been reported in those who abuse cocaine, an addictive psychostimulant like MA. Male cocaine users have decreased $\mathrm{rCBF}$ and $\mathrm{NAA} /$ creatine ratio, while female cocaine users had increased $\mathrm{rCBF}$ and higher myoinositol/creatine ratio in frontal white matter, compared to their gender-matched comparison subjects (Chang et al, 1999; Ernst et al, 2000b; Tucker et al, 2004).

Estrogen, a female sex hormone, may underlie the gender-MA interaction observed in the current study. Estrogen has been reported to have neuroprotective effects against MA exposure (Culmsee et al, 1999; Gao and Dluzen, 2001). Neuroprotective effects of estrogen can be mediated by a number of factors, including cardiovascular effects (Nabulsi et al, 1993), antioxidant effects (Sawada et al, 1998), inhibiting $\mathrm{Ca}^{2+}$ channels in striatal neurons (Mermelstein et al, 1996), inhibiting dopamine transporter function (Wirz-Justice et al, 1974), or reduction of MAinduced hyperthermia (Ali et al, 1996; Dluzen and McDermott, 2002).

However, only females, not males, have been reported to benefit from neuroprotective function of estrogen (Dluzen et al, 2002; Dluzen and McDermott, 2002). Therefore, other mediating factors, associated or nonassociated with estrogen, may also play important roles in gender-MA interaction. As glial response is associated with hypermetabolism (Roh et al, 1998), the absence of frontal hypometabolism in female MA users in the current study may be associated with enhanced glial repair response to MA in females rather than males. After MA exposure, female mice have been reported to express augmented mRNA of glial fibrillary acidic protein, which is associated with glial repair response to brain injury (Dluzen et al, 2003; Garcia-Segura et al, 1999).

Readers should be cautious in interpreting the comparison results between female MA users and female comparison subjects due to the small statistical power. However, consistent gender effects both in frontal metabolism and frontal executive functions in our study suggest the existence of gender differences in resistance against MA neurotoxicity in frontal lobes. Another limitation of our study was significant age difference between female and male MA users, as gender-MA interaction in the present study may be due to confounding age-MA interaction. However, there were no correlations of age with frontal metabolism or frontal executive function in the current study. In addition, there were no significant differences of age between male/female MA users and their gendermatched comparison subjects. Therefore, it was unlikely for our gender-MA interaction to be confounded by potential age-MA interaction.

Educational levels may have confounded our findings of decreased rGMRglc and increased errors in the WCST in MA users relative to healthy comparison subjects since there was a difference in educational levels between groups.
However, results were similar when analyses were covaried by educational levels. Consequently, our findings in MA users are likely to stem from the MA use rather than the difference in educational levels.

In addition, an HIV test was not conducted due to ethical and legal issues. As the risk of HIV infection in illegal drug users is high (Farabee et al, 2002), the effects of HIV infection on the findings cannot be totally excluded. However, the prevalence of HIV infection in the general population in Korea is very low relative to other countries. Furthermore, as Korean drug users can easily obtain syringes in pharmacies, only $1.1 \%$ of HIV infection is due to i.v. drug use in Korea (Kim et al, 2003). Additionally, we could not find any differences of brain volume between MA subjects and healthy comparison subjects, while patients with HIV infection have been reported to have smaller brain volumes, even in an asymptomatic state (Stout et al, 1998).

In conclusion, we report that abstinent MA users have decreased rCMRglc in frontal white matter and impaired frontal executive functions, and men are more vulnerable to these frontal neurotoxicities caused by MA use than women.

\section{ACKNOWLEDGEMENTS}

This work was supported by grants from the Health Technology Infrastructure Development Project of Korea Health Industry Development Institute (03-PJ1PG3-21300-0069).

\section{REFERENCES}

Ali SF, Newport GD, Slikker Jr W (1996). Methamphetamineinduced dopaminergic toxicity in mice. Role of environmental temperature and pharmacological agents. Ann NY Acad Sci 801: 187-198.

Chang L, Ernst T, Speck O, Patel H, DeSilva M, Leonido-Yee M et al (2002). Perfusion MRI and computerized cognitive test abnormalities in abstinent methamphetamine users. Psychiatry Res 114: 65-79.

Chang L, Ernst T, Strickland T, Mehringer CM (1999). Gender effects on persistent cerebral metabolite changes in the frontal lobes of abstinent cocaine users. Am J Psychiatry 156: 716-722.

Chung AI, Kang HK, Kwon JY, Hwang J, Yune SK, Chang KH et al (2004). Decreased frontal lobe gray matter densities in chronic detoxified methamphetamine user: voxel-based morphometry study. College on Problems of Drug Dependence annual meeting, San Juan, Puerto Rico.

Culmsee C, Vedder H, Ravati A, Junker V, Otto D, Ahlemeyer B et al (1999). Neuroprotection by estrogens in a mouse model of focal cerebral ischemia and in cultured neurons: evidence for a receptor-independent antioxidative mechanism. J Cereb Blood Flow Metab 19: 1263-1269.

Dluzen DE, Anderson LI, Pilati CF (2002). Methamphetaminegonadal steroid hormonal interactions: effects upon acute toxicity and striatal dopamine concentrations. Neurotoxicol Teratol 24: 267-273.

Dluzen DE, McDermott JL (2002). Estrogen, anti-estrogen, and gender: differences in methamphetamine neurotoxicity. Ann NY Acad Sci 965: 136-156.

Dluzen DE, Tweed C, Anderson LI, Laping NJ (2003). Gender differences in methamphetamine-induced mRNA associated with neurodegeneration in the mouse nigrostriatal dopaminergic system. Neuroendocrinology 77: 232-238. 
Ernst T, Chang L, Leonido-Yee M, Speck O (2000a). Evidence for long-term neurotoxicity associated with methamphetamine abuse: A 1H MRS study. Neurology 54: 1344-1349.

Ernst T, Chang L, Oropilla G, Gustavson A, Speck O (2000b). Cerebral perfusion abnormalities in abstinent cocaine abusers: a perfusion MRI and SPECT study. Psychiatry Res 99: 63-74.

Farabee D, Prendergast M, Cartier J (2002). Methamphetamine use and HIV risk among substance-abusing offenders in California. J Psychoactive Drugs 34: 295-300.

Friston KJ, Ashburner J, Frith CD, Poline JB, Heather JD, Frackowiak RSJ (1995a). Spatial registration and normalization of images. Hum Brain Mapp 2: 165-189.

Friston KJ, Holmes AP, Worsley KJ, Poline JP, Frith CD, Frackowiak RSL (1995b). Statistical parametric maps in functional imaging: a general liner approach. Hum Brain Mapp 2: $189-210$.

Gao X, Dluzen DE (2001). The effect of testosterone upon methamphetamine neurotoxicity of the nigrostriatal dopaminergic system. Brain Res 892: 63-69.

Garcia-Segura LM, Wozniak A, Azcoitia I, Rodriguez JR, Hutchison RE, Hutchison JB (1999). Aromatase expression by astrocytes after brain injury: implications for local estrogen formation in brain repair. Neuroscience 89: 567-578.

Hall JN, Broderick PM (1991). Community networks for response to abuse outbreaks of methamphetamine and its analogs. NIDA Res Monogr 115: 109-120.

Heaton RK, Chelune GJ, Kay KK, Curtiss G (1993). Wisconsin Card Sorting Test Manual: Revised and Expanded. Western Psychological Services: Los Angeles, CA.

Hirata H, Ladenheim B, Carlson E, Epstein C, Cadet JL (1996). Autoradiographic evidence for methamphetamine-induced striatal dopaminergic loss in mouse brain: attenuation in $\mathrm{CuZn}$ superoxide dismutase transgenic mice. Brain Res 714: 95-103.

Hwang J, Lee HY, Yune SK, Lee DS, Renshaw PF, Lyoo IK (2004). Decreased anterior cingulate activity in intravenous methamphetamine users: a single photon emission computed tomography and neuropsychologic test study. College on Problems of Drug Dependence annual meeting, San Juan, Puerto Rico.

Kalechstein AD, Newton TF, Green M (2003). Methamphetamine dependence is associated with neurocognitive impairment in the initial phases of abstinence. J Neuropsychiatry Clin Neurosci 15: 215-220.

Kim JM, Cho GJ, Hong SK, Chang KH, Chung JS, Choi YH et al (2003). Epidemiology and clinical features of HIV infection/ AIDS in Korea. Yonsei Med J 44: 363-370.

London ED, Simon SL, Berman SM, Mandelkern MA, Lichtman AM, Bramen J et al (2004). Mood disturbances and regional cerebral metabolic abnormalities in recently abstinent methamphetamine abusers. Arch Gen Psychiatry 61: 73-84.

McLellan AT, Luborsky L, Woody GE, O'Brien CP (1980). An improved diagnostic evaluation instrument for substance abuse patients. The Addiction Severity Index. J Nerv Ment Dis 168: 26-33.

Mermelstein PG, Becker JB, Surmeier DJ (1996). Estradiol reduces calcium currents in rat neostriatal neurons via a membrane receptor. J Neurosci 16: 595-604.

Nabulsi AA, Folsom AR, White A, Patsch W, Heiss G, Wu KK et al (1993). Association of hormone-replacement therapy with various cardiovascular risk factors in postmenopausal women. The Atherosclerosis Risk in Communities Study Investigators. $N$ Engl J Med 328: 1069-1075.

Nordahl TE, Salo R, Possin K, Gibson DR, Flynn N, Leamon M et al (2002). Low $N$-acetyl-aspartate and high choline in the anterior cingulum of recently abstinent methamphetamine-dependent subjects: a preliminary proton MRS study. Magnetic resonance spectroscopy. Psychiatry Res 116: 43-52.

Paulus MP, Hozack N, Frank L, Brown GG, Schuckit MA (2003). Decision making by methamphetamine-dependent subjects is associated with error-rate-independent decrease in prefrontal and parietal activation. Biol Psychiatry 53: 65-74.

Paulus MP, Hozack NE, Zauscher BE, Frank L, Brown GG, Braff DL et al (2002). Behavioral and functional neuroimaging evidence for prefrontal dysfunction in methamphetamine-dependent subjects. Neuropsychopharmacology 26: 53-63.

Pope Jr HG, Gruber AJ, Hudson JI, Huestis MA, Yurgelun-Todd D (2001). Neuropsychological performance in long-term cannabis users. Arch Gen Psychiatry 58: 909-915.

Preston KL, Wagner GC, Schuster CR, Seiden LS (1985). Long-term effects of repeated methylamphetamine administration on monoamine neurons in the rhesus monkey brain. Brain Res 338: $243-248$.

Roh JK, Nam H, Lee MC (1998). A case of central pontine and extrapontine myelinolysis with early hypermetabolism on 18FDG-PET scan. J Korean Med Sci 13: 99-102.

Sawada H, Ibi M, Kihara T, Urushitani M, Akaike A, Shimohama S (1998). Estradiol protects mesencephalic dopaminergic neurons from oxidative stress-induced neuronal death. J Neurosci Res 54 707-719.

Sekine Y, Minabe Y, Ouchi Y, Takei N, Iyo M, Nakamura K et al (2003). Association of dopamine transporter loss in the orbitofrontal and dorsolateral prefrontal cortices with methamphetamine-related psychiatric symptoms. Am J Psychiatry 160: $1699-1701$.

Shaw KP (1999). Human methamphetamine-related fatalities in Taiwan during 1991-1996. J Forensic Sci 44: 27-31.

Stout JC, Ellis RJ, Jernigan TL, Archibald SL, Abramson I, Wolfson $\mathrm{T}$ et al (1998). Progressive cerebral volume loss in human immunodeficiency virus infection: a longitudinal volumetric magnetic resonance imaging study. HIV Neurobehavioral Research Center Group. Arch Neurol 55: 161-168.

Tarairach J, Tournoux P (1988). Co-Planer Stereotaxic Atlas of the Human Brain. Thieme: New York, NY.

Thompson PM, Hayashi KM, Simon SL, Geaga JA, Hong MS, Sui $Y$ et al (2004). Structural abnormalities in the brains of human subjects who use methamphetamine. J Neurosci 24: 6028-6036.

Tucker KA, Browndyke JN, Gottschalk PC, Cofrancesco AT, Kosten TR (2004). Gender-specific vulnerability for rCBF abnormalities among cocaine abusers. Neuroreport 15: 797-801.

Volkow ND, Chang L, Wang GJ, Fowler JS, Ding YS, Sedler M et al (2001a). Low level of brain dopamine D2 receptors in methamphetamine abusers: association with metabolism in the orbitofrontal cortex. Am J Psychiatry 158: 2015-2021.

Volkow ND, Chang L, Wang GJ, Fowler JS, Franceschi D, Sedler M et al (2001b). Loss of dopamine transporters in methamphetamine abusers recovers with protracted abstinence. J Neurosci 21: 9414-9418.

Volkow ND, Chang L, Wang GJ, Fowler JS, Franceschi D, Sedler MJ et al (2001c). Higher cortical and lower subcortical metabolism in detoxified methamphetamine abusers. Am J Psychiatry 158: 383-389.

Vorhees CV, Ahrens KG, Acuff-Smith KD, Schilling MA, Fisher JE (1994). Methamphetamine exposure during early postnatal development in rats: I. Acoustic startle augmentation and spatial learning deficits. Psychopharmacology (Berl) 114: 392-401.

Wagner GC, Tekirian TL, Cheo CT (1993). Sexual differences in sensitivity to methamphetamine toxicity. J Neural Transm Gen Sect 93: 67-70.

Wang GJ, Volkow ND, Chang L, Miller E, Sedler M, Hitzemann R et al (2004). Partial recovery of brain metabolism in methamphetamine abusers after protracted abstinence. Am J Psychiatry 161: $242-248$.

Wilson JM, Kalasinsky KS, Levey AI, Bergeron C, Reiber G, Anthony RM et al (1996). Striatal dopamine nerve terminal 
markers in human, chronic methamphetamine users. Nat Med 2: 699-703.

Wirz-Justice A, Hackmann E, Lichtsteiner M (1974). The effect of oestradiol dipropionate and progesterone on monoamine uptake in rat brain. $J$ Neurochem 22: 187-189.

Woolverton WL, Cervo L, Johanson CE (1984). Effects of repeated methamphetamine administration on methamphetamine self- administration in rhesus monkeys. Pharmacol Biochem Behav 21: 737-741.

Yoo HJ, Song WY, Hwang SH, Kim SY, Kang JK, Lee SA et al (2000). Factor analysis of Wisconsin card sorting test as measures of frontal-lobe function in schizophrenia and in temporal lobe epilepsy. Korean J Psychol 19: 873-883. 